\title{
Whole-volume vs. segmental CT texture analysis of the liver to assess metachronous colorectal liver metastases
}

Citation for published version (APA):

Beckers, R. C. J., Beets-Tan, R. G. H., Schnerr, R. S., Maas, M., da Costa Andrade, L. A., Beets, G. L., Dejong, C. H., Houwers, J. B., \& Lambregts, D. M. J. (2017). Whole-volume vs. segmental CT texture analysis of the liver to assess metachronous colorectal liver metastases. Abdominal Radiology, 42(11), 2639-2645. https://doi.org/10.1007/s00261-017-1190-8

Document status and date:

Published: 01/11/2017

DOI:

10.1007/s00261-017-1190-8

Document Version:

Publisher's PDF, also known as Version of record

Document license:

Taverne

Please check the document version of this publication:

- A submitted manuscript is the version of the article upon submission and before peer-review. There can be important differences between the submitted version and the official published version of record.

People interested in the research are advised to contact the author for the final version of the publication, or visit the DOI to the publisher's website.

- The final author version and the galley proof are versions of the publication after peer review.

- The final published version features the final layout of the paper including the volume, issue and page numbers.

Link to publication

\footnotetext{
General rights rights.

- You may freely distribute the URL identifying the publication in the public portal. please follow below link for the End User Agreement:

www.umlib.nl/taverne-license

Take down policy

If you believe that this document breaches copyright please contact us at:

repository@maastrichtuniversity.nl

providing details and we will investigate your claim.
}

Copyright and moral rights for the publications made accessible in the public portal are retained by the authors and/or other copyright owners and it is a condition of accessing publications that users recognise and abide by the legal requirements associated with these

- Users may download and print one copy of any publication from the public portal for the purpose of private study or research.

- You may not further distribute the material or use it for any profit-making activity or commercial gain

If the publication is distributed under the terms of Article $25 \mathrm{fa}$ of the Dutch Copyright Act, indicated by the "Taverne" license above, 


\title{
Whole-volume vs. segmental CT texture analysis of the liver to assess metachronous colorectal liver metastases
}

\author{
R. C. J. Beckers, ${ }^{1,2,3,4}$ R. G. H. Beets-Tan, ${ }^{1,2}$ R. S. Schnerr, ${ }^{3}$ M. Maas, ${ }^{2}$ L. A. da Costa \\ Andrade, ${ }^{5}$ G. L. Beets, ${ }^{1,6}$ C. H. Dejong, ${ }^{4,7,8}$ J. B. Houwers, ${ }^{3}$ D. M. J. Lambregts ${ }^{2}$ \\ ${ }^{1}$ GROW School for Oncology and Developmental Biology, Maastricht University Medical Centre, Maastricht, The Netherlands \\ ${ }^{2}$ Department of Radiology, The Netherlands Cancer Institute, Amsterdam, The Netherlands \\ ${ }^{3}$ Department of Radiology, Maastricht University Medical Center, Maastricht, The Netherlands \\ ${ }^{4}$ Department of Surgery, Maastricht University Medical Center, Maastricht, The Netherlands \\ ${ }^{5}$ Medical Imaging Department and Faculty of Medicine, University Hospital of Coimbra, Coimbra, Portugal \\ ${ }^{6}$ Department of Surgery, The Netherlands Cancer Institute, Amsterdam, The Netherlands \\ ${ }^{7}$ NUTRIM School for Nutrition and Translational Research in Metabolism, Maastricht University, Maastricht, The Netherlands \\ ${ }^{8}$ Department of Surgery, RWTH Universitätsklinikum Aachen, Aachen, Germany
}

\begin{abstract}
Purpose: It is unclear whether changes in liver texture in patients with colorectal cancer are caused by diffuse (e.g., perfusional) changes throughout the liver or rather based on focal changes (e.g., presence of occult metastases). The aim of this study is to compare a whole-liver approach to a segmental (Couinaud) approach for measuring the CT texture at the time of primary staging in patients who later develop metachronous metastases and evaluate whether assessing CT texture on a segmental level is of added benefit.

Methods: 46 Patients were included: 27 patients without metastases (follow-up $>2$ years) and 19 patients who developed metachronous metastases within 24 months after diagnosis. Volumes of interest covering the whole liver were drawn on primary staging portal-phase CT. In addition, each liver segment was delineated separately. Mean gray-level intensity, entropy (E), and uniformity (U) were derived with different filters ( $\sigma 0.5-2.5)$. Patients/segments without metastases and patients/segments that later developed metachronous metastases were compared using independent samples $t$ tests.

Results: Absolute differences in entropy and uniformity between the group without metastases and the group with metachronous metastases group were consistently smaller for the segmental approach compared to the
\end{abstract}

Correspondence to: D. M. J. Lambregts; email: d.lambregts@nki.nl whole-liver approach. No statistically significant differences were found in the texture measurements between both groups.

Conclusions: In this small patient cohort, we could not demonstrate a clear predictive value to identify patients at risk of developing metachronous metastases within 2 years. Segmental CT texture analysis of the liver probably has no additional benefit over whole-liver texture analysis.

Key words: Colorectal cancer-Liver metastases - CT texture-Occult disease-Metachronous metastases-Micro metastases

With \pm 750.000 new cases every year worldwide, colorectal cancer (CRC) constitutes one of the most common forms of cancer [1]. The most prevalent site of metastases in CRC is the liver (77\%). At time of diagnosis approximately $20 \%$ of patients have metastatic disease [2-5]. An additional 5\% of patients will develop metachronous metastases within the first year, increasing to $15 \%$ after 5 years [3]. The exact pathogenesis of the development of colorectal liver metastases is still not fully understood [6-8]. A recent review suggested that there might be a difference in biological characteristics between synchronous and metachronous metastases with synchronous metastases showing a more aggressive disease profile with poorer survival rates [9]. However, 
other studies reported no difference in survival after resection of liver metastases, whether they appeared synchronously or metachronously [10-12]. A better understanding of the exact pathogenesis of the development of metachronous metastases could be of great influence on clinical practice; knowing which patients are at risk of developing metachronous disease might create opportunities for (neo-) adjuvant treatment and could affect the intensity of follow-up.

Imaging might play a role in this regard. The idea would be that at the early stage of metachronous disease development, changes are already occurring within the liver before any focal liver lesions become apparent. These early changes cannot be observed with common morphological imaging techniques, but may be detected with more sophisticated imaging or post processing techniques. A specific technique that has shown promise is CT texture analysis. Texture analysis is a mathematical approach to quantify the distribution of gray-level values within tissues, thereby providing a measure of tissue heterogeneity [13]. Texture features derived from colorectal liver metastases as well as from the surrounding liver parenchyma have both been reported to correlate with patient survival $[14,15]$. Moreover, previous reports have shown that differences in the overall liver texture can be observed on CT between patients with and without liver metastases. Similarly, even at the time of primary staging in patients that develop metachronous metastases, texture changes can be observed, particularly in patients who develop metastases early (within 6 months) after diagnosis [16, 17]. However, results reported so far are ambiguous, and convincing evidence supporting the role of $\mathrm{CT}$ texture analysis to predict patients at risk for developing metachronous liver disease has yet to be provided.

A potential limiting factor could be the methodology of obtaining texture measures. So far, whole-liver texture analyses have been performed, based on the assumption that early changes in the liver preceding the manifestation of visible focal liver lesions occur diffusely in the liver parenchyma and are likely to be related to changes in liver perfusion [18-20]. An alternative hypothesis would be that these early changes are more localized to a certain area within the liver (i.e., the specific site where at a later stage the metastases will become visible) and are more related to focal changes on a cellular level (i.e., presence of occult micro metastases) and/or focal perfusional changes $[14,21]$. In the latter case, a whole-liver approach will likely not be sensitive enough to detect these focal changes, and a segmental analysis of the liver texture might provide better results.

The aim of this study therefore was to evaluate this hypothesis and get a better insight in the distribution of textural changes within the liver (i.e., diffuse vs. focal) by comparing the CT liver texture of patients without metastases and patients with metachronous liver disease using a 'whole liver' vs. 'segmental' approach.

\section{Method and materials}

\section{Patients}

This study retrospectively analyzed 46 patients who were treated for colorectal cancer at Maastricht University Medical Center between August 2009 and November 2013. Informed consent was waived by the local ethical committee. Part of the study patients (44/46) were included in a previously reported multicentre study cohort [17]. As part of their primary staging all patients routinely underwent contrast-enhanced abdominal or liver CT. Two groups of patients were defined: (A) the "no metastases' (control) group, consisting of 27 patients who had no evidence of liver metastases at primary staging, nor during at least 2 years of follow-up and (B) the 'metachronous metastases' group consisting of 19 consecutive patients who had no evidence of liver metastases at primary staging but developed metachronous liver metastases within 24 months after the primary staging. The inclusion criteria consisted of (a) histopathologically confirmed colorectal adenocarcinoma, (b) no extrahepatic metastases, and (c) a primary staging CT including a portal venous phase (PVP). Exclusion criteria consisted of $(a)$ previous liver surgery, (b) previous systemic treatment (chemotherapy), (c) diffuse hepatic metastases, leaving no normal segments to compare, and $(d)$ evidence of other diffuse liver disease such as steatosis or cirrhosis.

\section{CT acquisition}

All CT scans included a PVP scan of the liver and were acquired using multi-slice CT equipment (Philips Brilliance 64, Philips Medical Systems, Best, The Netherlands; Siemens SOMATOM Sensation 16 or SOMATOM Definition Flash, Siemens Healthcare, Erlangen, Germany). PVP images were obtained with a tube voltage of $120 \mathrm{kVp}$. The contrast medium (Ultravist $300 \mathrm{mgI} / \mathrm{ml}$; Iopromide, Bayer Healthcare, Berlin, Germany) was prewarmed to $37^{\circ} \mathrm{C}\left(99^{\circ} \mathrm{F}\right)$ and administered intravenously as a bolus injection of $110 \mathrm{ml}$ at a rate of $3.5 \mathrm{ml} / \mathrm{s}$, followed by a saline flush of $40 \mathrm{ml}$. The scan delay for the PVP was set at $70 \mathrm{~s}$ with a (reconstructed) slice thickness of $5 \mathrm{~mm}$.

\section{Whole-volume vs. segmental liver delineation}

All delineations were performed on the initial staging CTs (when all patients were still without any visible colorectal liver metastases). The PVP images were transferred to an offline workstation for liver delineation 
which was performed using the open-source software tool MRIcron [22]. Liver delineation was performed in two ways (see Fig. 1): (a) whole-liver delineation, and (b) segmental delineation. For the whole-liver delineation a single reader (RB) delineated the whole-liver volume (excluding the border of the liver, any visible benign lesions, the inferior vena cava, caudate lobe, large hepatic veins, arteries, and biliary vessels) according to methods previously reported $[16,17]$. For the segmental delineation, individual liver segments were delineated, based on Couinaud's classification [23]. Seven segments were included $(2,3,4 \mathrm{ab}, 5,6,7,8)$. The caudate lobe was excluded, since it is often difficult to discern from the border of the vena cava.

\section{Texture analysis}

2D Texture analysis was performed with a dedicated script written in MATLAB (The MathWorks Inc., Natick, MA, 2000) by one of the authors (RSS), according to methods previously reported [16, 17, 24]. The mathematical analysis technique used for this study comprises two main stages: image filtration followed by the quantification of texture. For image filtration, a Laplacian of Gaussian (LoG) band-pass filter was chosen which was applied in the Fourier space. A reference resolution of $0.84 \mathrm{~mm}$ was chosen and for each CT scan with a different resolution, the width of the LoG-filter $(\sigma)$ was modified to keep the physical size (in $\mathrm{mm}$ ) of the filter constant. A fine $(\sigma=0.5)$, medium $(\sigma=1.5)$, and a coarse filter $(\sigma=2.5)$ were used. For quantification of the texture of the liver parenchyma, mean gray-level intensity (M), entropy (E), and uniformity (U) were used.
These features were calculated from a histogram based on the points within the region of interest with a bin size of one Hounsfield unit. $\mathrm{M}$ is the number of bins in the histogram; entropy is based on the width of the histogram; and uniformity is based on the narrowness.

\section{Standard of reference}

In the patients without metastases, the absence of metastases was confirmed by means of clinical follow-up including regular carcinoembryonic antigen (CEA) level and imaging (CT and in some cases US and/or MRI). The median follow-up time was 54 months (range 35-57 months). In the metachronous metastases group, the presence of metachronous liver lesions was confirmed by histopathology in 10 patients, by growth over time in 5 patients, and by corresponding FDG-PET positivity (after initial CT diagnosis) in 4 patients.

\section{Statistical analysis}

Statistical analyses were performed using the Statistical Package for the Social Sciences (IBM Corp. Released 2012. IBM SPSS Statistics for Windows, Version 21.0. Armonk, NY: IBM Corp.) and Stata (StataCorp. 2009. Stata Statistical Software: Release 11. College Station, TX: StataCorp LP). Baseline patient characteristics were assessed and compared using descriptive statistics. Patients/segments without metastases and with metachronous metastases were compared using independent samples $t$ test, Mann-Whitney $U$ test was used for nonparametric data. For the segmental analysis, segments analyzed on the initial staging CT were matched to seg-

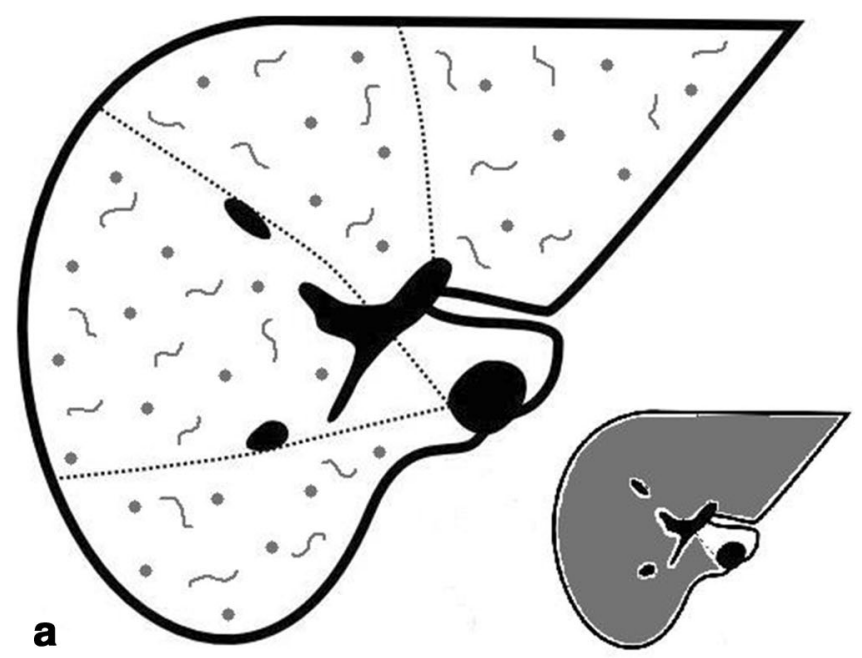

Fig. 1. Illustration of the hypothetical concept that textural changes are caused either (A) by changes (e.g., perfusional and/or cellular) occurring diffusely throughout the liver, which can be expected to become most apparent with a whole-vol-

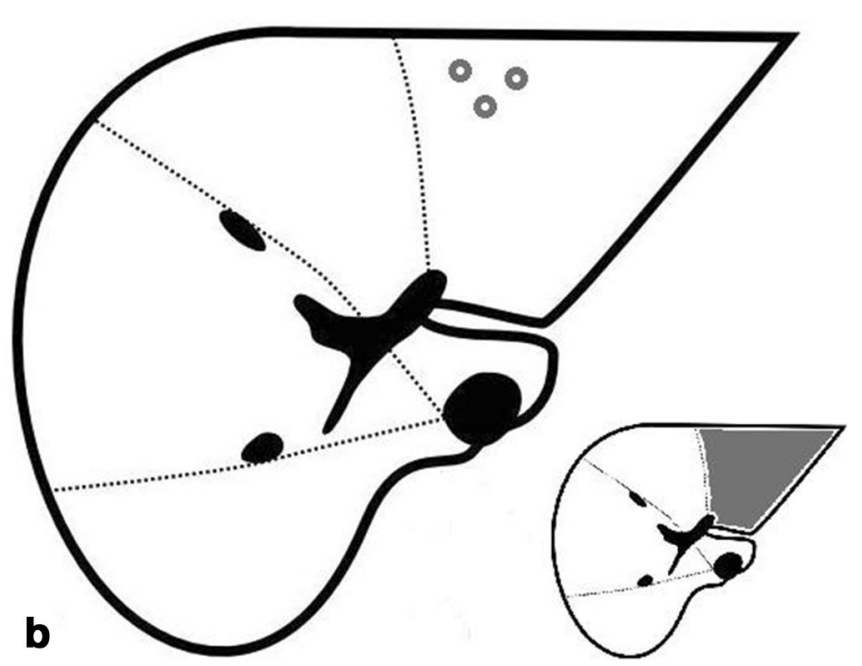

ume liver delineation, or (B) by more focally situated changes in the liver caused, for example, by the presence of occult micrometastases, which can be expected to become more apparent with a segmental liver delineation. 
ments where disease occurred during follow-up. A $P$ value $<0.05$ was considered to indicate statistical significance.

\section{Results}

\section{Patient characteristics}

Of the 46 patients enrolled in the study, 29 patients were male and 17 were female. Median age was 66.5 years (range 44-81 years). The primary tumor was located in the colon in 24 patients and in the rectum in the other 22 patients. Baseline characteristics of the study patients including results per subgroup are given in Table 1. Nineteen patients developed metachronous metastases with a median diagnosis-metastases interval of 12 months (range 4-20 months). In 1 patient, metastases occurred within 6 months, in 9 within 7-12 months, and in 9 within 13-24 months. A total of 322 segments were delineated. Of these, 189 segments $(58.7 \%)$ remained without metastases; in 37 segments (11.5\%) metastases occurred during follow-up. Only segments of the patients who remained without metastases were included in the analysis.

\section{Whole-liver vs. segmental approach}

Table 2 compares the texture values between the no metastases and metachronous metastases group for the whole-liver vs. the segmental approach. The absolute difference in entropy and uniformity values between the no metastases and metachronous metastases group was consistently smaller for the segmental approach (difference $0.00-0.11$ for entropy and $0.13-1.53$ for uniformity) compared to the whole-volume approach (difference $0.03-0.15$ for entropy and $0.70-2.29$ for uniformity). For mean intensity at fine image filtration, the same effect was observed. None of the whole-liver nor segmental texture measurements resulted in any statistically significant differences between the no metastases and metachronous metastases group.

\section{Discussion}

The aim of this study was to get a better insight in the underlying cause of textural changes that can be observed on CT of the liver in patients with colorectal liver metastases. We compared a whole-liver approach with a segmental approach using Couinaud's segments to study

Table 1. Baseline characteristics of the 46 patients

\begin{tabular}{|c|c|c|c|}
\hline \multirow[t]{2}{*}{ Characteristics } & \multicolumn{2}{|c|}{ Group } & \multirow[t]{2}{*}{ Total $(N=46)$} \\
\hline & $\mathrm{A}(N=27)$ & $\mathrm{B}(N=19)$ & \\
\hline \multicolumn{4}{|l|}{ Age (year) } \\
\hline Median & 66 & 67 & 66.5 \\
\hline Range & $44-76$ & $47-81$ & $44-81$ \\
\hline \multicolumn{4}{|l|}{ Sex } \\
\hline Male & $17(63)$ & $12(63.2)$ & $29(63)$ \\
\hline Female & $10(37)$ & $7(36.8)$ & $17(37)$ \\
\hline \multicolumn{4}{|l|}{ Primary tumor site } \\
\hline Rectum & $15(55.6)$ & $7(36.8)$ & $22(47.8)$ \\
\hline Colon & $12(44.4)$ & $12(63.2)$ & $24(52.2)$ \\
\hline \multicolumn{4}{|l|}{ Tumor stage* } \\
\hline T1 & 0 & 0 & 0 \\
\hline $\mathrm{T} 2$ & $7(25.9)$ & 0 & $7(15.2)$ \\
\hline $\mathrm{T} 3$ & $17(63.0)$ & $12(63.2)$ & $29(63.0)$ \\
\hline \multirow{2}{*}{\multicolumn{4}{|c|}{$\begin{array}{c}14 \\
\text { Nodal stage* }\end{array}$}} \\
\hline & & & \\
\hline No & $11(40.7)$ & $3(15.8)$ & $14(30.4)$ \\
\hline N1 & $4(14.8)$ & $6(31.6)$ & $10(21.7)$ \\
\hline N2 & $12(44.4)$ & $10(52.6)$ & $22(47.8)$ \\
\hline \multicolumn{4}{|l|}{ Histology of primary tumor } \\
\hline Adenocarcinoma n.o.s. & $19(70.4)$ & $14(73.7)$ & $33(71.7)$ \\
\hline Mucinous & $6(22.2)$ & $3(15.8)$ & $9(19.6)$ \\
\hline Signet-ring cell carcinoma & $1(3.7)$ & $2(10.5)$ & $3(6.5)$ \\
\hline & $1(3.7)$ & 0 & $1(2.1)$ \\
\hline \multicolumn{4}{|l|}{ Time until metastases $(\mathrm{m})^{\dagger}$} \\
\hline Median & $\mathrm{N} / \mathrm{A}$ & 12 & $\mathrm{~N} / \mathrm{A}$ \\
\hline Range & $\mathrm{N} / \mathrm{A}$ & $4-20$ & $\mathrm{~N} / \mathrm{A}$ \\
\hline \multicolumn{4}{|c|}{ Carcinoembryonic antigen (CEA) at time of primary diagnosis } \\
\hline Normal $(<5 \mathrm{mcg} / \mathrm{L})$ & $18(66.7)$ & $9(47.4)$ & 27 (58.7) \\
\hline Elevated $(\geq 5 \mathrm{mcg} / \mathrm{L})$ & $8(29.6)$ & $8(42.1)$ & $16(34.8)$ \\
\hline
\end{tabular}

Unless otherwise indicated, data are numbers of patients and data in parentheses are percentages

Group A: patients without liver metastases

Group B: patients with metachronous liver metastases within 24 months after primary staging

$N / A$ not applicable

* Primary tumor/nodal stage was based on histopathology for patients undergoing direct surgery and based on MRI for patients undergoing neoadjuvant treatment

${ }^{\dagger}$ Interval between the primary staging $\mathrm{CT}$ and the detection of liver metastases 
Table 2. Mean ( \pm Standard Deviation) of CT texture features of the apparently non-diseased liver parenchyma measured at different scale values $(\sigma)$ on PVP CT

\begin{tabular}{|c|c|c|c|c|c|c|}
\hline \multirow[t]{2}{*}{ Texture features } & \multicolumn{3}{|c|}{ Whole liver } & \multicolumn{3}{|c|}{ Segments } \\
\hline & $\mathrm{A}(N=27)$ & $\mathrm{B}(N=19)$ & Difference* & $\mathrm{A}(N=189)$ & B $(N=37)$ & Difference* \\
\hline \multicolumn{7}{|c|}{ Mean gray-level intensity } \\
\hline Unfiltered & $114.33 \pm 18.38$ & $113.35 \pm 15.68$ & 0.98 & $114.53 \pm 18.27$ & $117.34 \pm 17.92$ & 2.81 \\
\hline$\sigma=0.5$ & $-0.018 \pm 0.087$ & $-0.044 \pm 0.081$ & 0.026 & $0.034 \pm 0.147$ & $0.043 \pm 0.130$ & 0.009 \\
\hline$\sigma=1.5$ & $0.36 \pm 0.18$ & $0.34 \pm 0.22$ & 0.02 & $0.44 \pm 0.25$ & $0.51 \pm 0.29$ & 0.07 \\
\hline$\sigma=2.5$ & $1.25 \pm 0.40$ & $1.20 \pm 0.52$ & 0.05 & $1.33 \pm 0.45$ & $1.44 \pm 0.56$ & 0.11 \\
\hline \multicolumn{7}{|l|}{ Entropy } \\
\hline Unfiltered & $5.71 \pm 0.18$ & $5.67 \pm 0.36$ & 0.03 & $5.65 \pm 0.19$ & $5.63 \pm 0.32$ & 0.02 \\
\hline$\sigma=0.5$ & $7.02 \pm 0.21$ & $6.87 \pm 0.66$ & 0.15 & $7.02 \pm 0.21$ & $6.91 \pm 0.53$ & 0.11 \\
\hline$\sigma=1.5$ & $7.06 \pm 0.18$ & $6.97 \pm 0.33$ & 0.09 & $7.03 \pm 0.20$ & $6.98 \pm 0.30$ & 0.05 \\
\hline$\sigma=2.5$ & $6.52 \pm 0.17$ & $6.45 \pm 0.24$ & 0.07 & $6.45 \pm 0.19$ & $6.45 \pm 0.24$ & 0.00 \\
\hline \multicolumn{7}{|l|}{ Uniformity } \\
\hline Unfiltered & $22.82 \pm 2.94$ & $24.12 \pm 6.80$ & 1.30 & $23.84 \pm 3.29$ & $25.01 \pm 6.45$ & 1.17 \\
\hline$\sigma=0.5$ & $9.26 \pm 1.41$ & $11.55 \pm 7.07$ & 2.29 & $9.16 \pm 1.41$ & $10.69 \pm 5.33$ & 1.53 \\
\hline$\sigma=1.5$ & $8.99 \pm 1.14$ & $9.75 \pm 2.42$ & 0.76 & $9.16 \pm 1.28$ & $9.61 \pm 2.16$ & 0.45 \\
\hline$\sigma=2.5$ & $13.32 \pm 1.58$ & $14.02 \pm 2.38$ & 0.70 & $13.88 \pm 1.87$ & $14.01 \pm 2.43$ & 0.13 \\
\hline
\end{tabular}

Group A: patients/segments without liver metastases

Group B: patients/segments with metachronous liver metastases within 24 months following primary staging

* Differences were not statistically significant between the no metastases and metachronous metastases patients/segments for any of the features

whether changes in liver texture are most likely caused by focal or diffuse liver pathology. The hypothesis was that in case of occult focal disease (micro metastases) the differences on a segmental level would be more apparent, whereas conversely diffuse changes in liver texture would become more apparent using a whole-liver approach. Although the observed differences are altogether small (and not statistically significant), our results suggest that differences in texture between patients without metastases and patients who develop metastatic liver $\leq 2$ years after initial diagnosis are more pronounced for the whole-liver approach. No additional effect was found for texture measurements on a segmental level.

It has been suggested that diffuse changes in the liver preceding the development of focal liver metastases are probably related to changes in liver perfusion and hepatic hemodynamics [14, 18]. Tumor progression towards metastasis is a process with multiple stages in which malignant cells spread from the primary colorectal tumor to colonize the liver $[25,26]$. Paget's "seed and soil" theory for metastasis states that an adequate microenvironment is required for malignant cells to nest into distant tissues and form metastases [27]. This microenvironment should support malignant cell maintenance and regulate cell function and proliferation so that tumor cells are able to form into clinically detectable metastases $[28,29]$. One of the key elements in the progression from micro metastasis to visible metastases is the assembly of a functional vascular structure to enable cellular expansion [30-32]. These changes lead to physiological changes such as increased perfusion, blood volume, and capillary permeability [33]. It is known that in the liver, tumor angiogenesis occurs when metastases reach approximately $0.5 \mathrm{~mm}$ in size, while lesions can only be visualized with conventional morphological imaging techniques when they reach at least $3-5 \mathrm{~mm}$ in diameter [34]. These observations may explain why changes in the liver texture may already be observed on a whole-liver level (as was reported in previous studies [16, 17]), while no visible metastases have yet become apparent [35]. Despite the fact that differences in our study also appeared to be most pronounced for the whole-liver approach, we could not confirm a statistically significant difference in texture between patients without metastases and patients who later developed metachronous metastases. A possible contributing factor could be that the median interval between the primary staging $\mathrm{CT}$ and the development of metastatic lesions in our study was 12 months, whereas Beckers et al. previously reported that CT texture was only able to predict metastases occurring early (within 6 months) after primary CRC diagnosis [17]. Our current study cohort was too small to perform meaningful subgroup analyses on the development of early metastases (given that only in 1 patient metastases occurred within 6 months).

Our findings support doubts raised in previous papers with respect to the robustness of texture analysis as a self-contained image quantification method and the current lack of evidence from large-scale prospective studies [17, 36]. Most likely texture analysis should be used as an adjunct to other parameters, clinical, laboratory, and imaging, with the ultimate aim to develop a comprehensive global clinical prediction model. From the imaging perspective, not only CT texture analysis should be further explored, but also other techniques that have shown promise in previous reports such as diffusion-weighted imaging [37], perfusion CT and MR imaging [38, 39], and ultrasound Doppler [40].

There are some limitations to our study. The sample size of patients with metachronous metastases (particu- 
larly patients with early metastases) was small. Second, slice thickness in our study was relatively large. Third, image segmentations were only performed by a single reader, although we believe that, given the method of whole-liver segmentation and segmentations according to the standardized and well-known Couinaud classification, potential effects of interobserver variations can be expected to be limited. Finally, a major limitation is that it is not possible to correlate our findings with underlying histopathological changes in the liver as this would require invasive procedures such as routine liver biopsy, which is not feasible from an ethical perspective. Moreover, in the patients who developed metachronous metastases, histopathologic confirmation was only available in $10 / 19$ patients.

\section{Conclusion}

Our study showed no added value for segmental texture analysis over whole-liver CT texture analysis. Despite the lack of pathologic correlation, our results appear to favor the hypothesis that textural changes are more likely based on diffuse, (perfusional) changes, rather than changes occurring on a more focal (segmental) level. Future prospective studies should focus on determining the role of CT texture analysis - as well as other imaging techniques-within the complete spectrum of clinical, laboratory, and imaging parameters to develop a clinically meaningful predictive model that can truly impact clinical decision making.

\section{Compliance with ethical standards}

Funding No funding was received for this study.

Conflict of interest The authors declare that they have no conflict of interest.

Ethical approval All procedures performed in this study were in accordance with the ethical standards of the international and/or national research committee and with the 1964 Helsinki Declaration and its later amendments or comparable ethical standards.

Informed consent Due to the retrospective nature of the study informed consent was waived.

\section{References}

1. Tanaka S, Imamura Y (2006) International comparisons of cumulative risk of colorectal cancer, from cancer incidence in five continents, vol. VIII. Jpn J Clin Oncol 36(3):186-187. doi: $10.1093 / \mathrm{jjco} / \mathrm{hyi} 249$

2. Siegel RL, Miller KD, Jemal A (2015) Cancer statistics, 2015. CA 65(1):5-29. doi:10.3322/caac. 21254

3. Manfredi S, Lepage C, Hatem C, et al. (2006) Epidemiology and management of liver metastases from colorectal cancer. Ann Surg 244(2):254-259. doi:10.1097/01.sla.0000217629.94941.cf

4. Hess KR, Varadhachary GR, Taylor SH, et al. (2006) Metastatic patterns in adenocarcinoma. Cancer 106(7):1624-1633. doi: $10.1002 /$ cncr. 21778

5. Landreau P, Drouillard A, Launoy G, et al. (2015) Incidence and survival in late liver metastases of colorectal cancer. J Gastroenterol Hepatol 30(1):82-85. doi:10.1111/jgh.12685
6. Rudmik LR, Magliocco AM (2005) Molecular mechanisms of hepatic metastasis in colorectal cancer. J Surg Oncol 92(4):347-359. doi: $10.1002 /$ jso. 20393

7. Wang SC, Lin JK, Wang HS, et al. (2010) Nuclear expression of CXCR4 is associated with advanced colorectal cancer. Int $\mathbf{J}$ Colorectal Dis 25(10):1185-1191. doi:10.1007/s00384-010-0999-1

8. Slesser AA, Georgiou P, Brown G, et al. (2013) The tumour biology of synchronous and metachronous colorectal liver metastases: a systematic review. Clin Exp Metastasis 30(4):457-470. doi: 10.1007/s10585-012-9551-8

9. Tan EK, Ooi LL (2010) Colorectal cancer liver metastases - understanding the differences in the management of synchronous and metachronous disease. Ann Acad Med Singapore 39(9):715-719

10. Li ZQ, Liu K, Duan JC, et al. (2013) Meta-analysis of simultaneous versus staged resection for synchronous colorectal liver metastases. Hepatol Res 43(1):72-83. doi:10.1111/j.1872-034X.2012.01050.x

11. Yin Z, Liu C, Chen Y, et al. (2013) Timing of hepatectomy in resectable synchronous colorectal liver metastases (SCRLM): simultaneous or delayed? Hepatology 57(6):2346-2357. doi:10. $1002 /$ hep. 26283

12. Slesser AA, Simillis C, Goldin R, et al. (2013) A meta-analysis comparing simultaneous versus delayed resections in patients with synchronous colorectal liver metastases. Surg Oncol 22(1):36-47. doi: $10.1016 / j$.suronc.2012.11.002

13. Castellano G, Bonilha L, Li LM, Cendes F (2004) Texture analysis of medical images. Clin Radiol 59(12):1061-1069. doi: 10.1016/j.crad.2004.07.008

14. Ganeshan B, Miles KA, Young RC, Chatwin CR (2007) Hepatic enhancement in colorectal cancer: texture analysis correlates with hepatic hemodynamics and patient survival. Acad Radiol 14(12):1520-1530. doi:10.1016/j.acra.2007.06.028

15. Lubner MG, Stabo N, Lubner SJ, et al. (2015) CT textural analysis of hepatic metastatic colorectal cancer: pre-treatment tumor heterogeneity correlates with pathology and clinical outcomes. Abdom Imaging 40(7):2331-2337. doi:10.1007/s00261-015-0438-4

16. Rao SX, Lambregts DM, Schnerr RS, et al. (2014) Whole-liver CT texture analysis in colorectal cancer: does the presence of liver metastases affect the texture of the remaining liver? United Eur Gastroenterol J 2(6):530-538. doi:10.1177/2050640614552463

17. Beckers RCJ, Lambregts DMJ, Schnerr RS, et al. (2017) Whole liver CT texture analysis to predict the development of colorectal liver metastases - A multicentre study. Eur J Radiol 92:64-71. doi: 10.1016/j.ejrad.2017.04.019

18. Ganeshan B, Miles KA, Young RC, Chatwin CR (2007) In search of biologic correlates for liver texture on portal-phase CT. Acad Radiol 14(9):1058-1068. doi:10.1016/j.acra.2007.05.023

19. Leen E (1999) The detection of occult liver metastases of colorectal carcinoma. J Hepatobiliary Pancreat Surg 6(1):7-15

20. Kruskal JB, Thomas P, Kane RA, Goldberg SN (2004) Hepatic perfusion changes in mice livers with developing colorectal cancer metastases. Radiology 231(2):482-490. doi:10.1148/radiol.231 2030160

21. Cuenod C, Leconte I, Siauve N, et al. (2001) Early changes in liver perfusion caused by occult metastases in rats: detection with quantitative CT. Radiology 218(2):556-561

22. Rorden C, Karnath HO, Bonilha L (2007) Improving lesionsymptom mapping. J Cognitive Neurosci 19(7):1081-1088. doi: 10.1162/jocn.2007.19.7.1081

23. Couinaud C (1957) Le foie: études anatomiques et chirurgicales. Masson \& Cie

24. Rao SX, Lambregts DM, Schnerr RS, et al. (2016) CT texture analysis in colorectal liver metastases: a better way than size and volume measurements to assess response to chemotherapy? United Eur Gastroenterol J 4(2):257-263. doi:10.1177/2050640615601603

25. Gupta GP, Massague J (2006) Cancer metastasis: building a framework. Cell 127(4):679-695. doi:10.1016/j.cell.2006.11.001

26. Weinberg R (2013) The biology of cancer. Garland science

27. Paget S (1989) The distribution of secondary growths in cancer of the breast. 1889. Cancer Metastasis Rev 8(2):98-101

28. Kaplan RN, Riba RD, Zacharoulis S, et al. (2005) VEGFR1positive haematopoietic bone marrow progenitors initiate the premetastatic niche. Nature 438(7069):820-827. doi:10.1038/nature 04186 
29. Eveno C, Hainaud P, Rampanou A, et al. (2015) Proof of prometastatic niche induction by hepatic stellate cells. J Surg Res 194(2):496-504. doi:10.1016/j.jss.2014.11.005

30. Holmgren L, O'Reilly MS, Folkman J (1995) Dormancy of micrometastases: balanced proliferation and apoptosis in the presence of angiogenesis suppression. Nat Med 1(2):149-153

31. Naumov GN, Akslen LA, Folkman J (2006) Role of angiogenesis in human tumor dormancy: animal models of the angiogenic switch. Cell Cycle 5(16):1779-1787. doi:10.4161/cc.5.16.3018

32. Hicklin DJ, Ellis LM (2005) Role of the vascular endothelial growth factor pathway in tumor growth and angiogenesis. J Clin Oncol 23(5):1011-1027. doi:10.1200/JCO.2005.06.081

33. Miles KA, Leggett DA, Kelley BB, et al. (1998) In vivo assessment of neovascularization of liver metastases using perfusion $\mathrm{CT}$. Br J Radiol 71(843):276-281. doi:10.1259/bjr.71.843.9616236

34. Archer SG, Gray BN (1989) Vascularization of small liver metastases. Br J Surg 76(6):545-548

35. Allison KH, Fligner CL, Parks WT (2004) Radiographically occult, diffuse intrasinusoidal hepatic metastases from primary breast carcinomas: a clinicopathologic study of 3 autopsy cases. Arch Pathol Lab Med 128(12):1418-1423. doi:10.1043/1543-2165(2004)
36. Chalkidou A, O'Doherty MJ, Marsden PK (2015) False discovery rates in PET and CT studies with texture features: a systematic review. PLoS ONE 10(5):e0124165. doi:10.1371/journal. pone. 0124165

37. Lambregts DM, Martens MH, Quah RC, et al. (2015) Whole-liver diffusion-weighted MRI histogram analysis: effect of the presence of colorectal hepatic metastases on the remaining liver parenchyma. Eur J Gastroenterol Hepatol 27(4):399-404. doi:10.1097/MEG.0 000000000000316

38. Tsushima Y, Blomley MJ, Yokoyama H, Kusano S, Endo K (2001) Does the presence of distant and local malignancy alter parenchymal perfusion in apparently disease-free areas of the liver? Dig Dis Sci 46(10):2113-2119

39. White MJ, O'Gorman RL, Charles-Edwards EM, et al. (2007) Parametric mapping of the hepatic perfusion index with gadolinium-enhanced volumetric MRI. Br J Radiol 80(950):113-120. doi: $10.1259 / \mathrm{bjr} / 36793733$

40. Kopljar M, Patrlj L, Busic Z, et al. (2014) Potential use of Doppler perfusion index in detection of occult liver metastases from colorectal cancer. Hepatobiliary Surg Nutr 3(5):259-267. doi: $10.3978 /$ j.issn.2304-3881.2014.09.04 